\title{
Standardization of the Subjective Happiness Scale (SHS) in a Greek Sample
}

\author{
Eirini Karakasidou, Christos Pezirkianidis, Anastassios Stalikas, Michael Galanakis
}

Panteion University of Social and Political Sciences, Athens, Greece

Email: galanakismichael@hotmail.com

How to cite this paper: Karakasidou, E., Pezirkianidis, C., Stalikas, A., \& Galanakis, M. (2016). Standardization of the Subjective Happiness Scale (SHS) in a Greek Sample. Psychology, 7, 1753-1765. http://dx.doi.org/10.4236/psych.2016.714164

Received: October 5, 2016

Accepted: November 26, 2016

Published: November 29, 2016

Copyright $\odot 2016$ by authors and Scientific Research Publishing Inc. This work is licensed under the Creative Commons Attribution International License (CC BY 4.0). http://creativecommons.org/licenses/by/4.0/

\begin{abstract}
Positive psychology focuses on the beneficial effects of positive variables in human health. Research on positive emotions variables has increased vastly over the last years due to the role that these variables play on psychological health. In this context, subjective happiness is a variable that has garnered increasing interest as it is believed to play a crucial role in well-being and happiness overall. In the present study, we examined the psychometric properties of one of the newest and most prominent tools for the measurement of Subjective Happiness, the Subjective Happiness Scale (SHS). The standardization was carried out in a sample of 6948 Greek Adults, ranging from 18 - 79 years old. Results showed that the SHS has satisfactory reliability and validity indexes. Moreover, the factorial structure of the scale matches the ones found in previous studies in numerous countries. Further implications and application opportunities are discussed.
\end{abstract}

\section{Keywords}

Subjective Happiness, Well Being, Positive Psychology, Greek Validation, Reliability, Validity, Psychometric Properties

\section{Introduction}

Subjective happiness is a variable that has garnered increasing interest with the development of positive psychology, the study of the conditions and processes that contribute to the flourishing or optimal functioning of people, groups and institutions (Gable \& Haidt, 2005; Seligman \& Csikzentmihalyi, 2000). A variety of biological, psychological and philosophical approaches have striven to define happiness and identify its sources. (Diener, Suh, Lucas, \& Smith, 1999) definition of happiness has become widely accepted within the scientific community. They define it as a combination of three components: infrequent instances of negative effect, frequent instances of positive ef- 
fect, and a high level of life satisfaction. In this regard, positive effect, negative effect, and life satisfaction are considered as indicators of the same construct, highly correlated, and typically yield a single dimension to be closely related to happiness, because they involve evaluative judgments based on individuals' experiences. According to this definition, happiness might be conceptualized as a subjective state, with the consequence that self-reporting instruments are the typical way of determining how happy an individual is. Most individuals are capable of reporting their degree of happiness or unhappiness, this judgment not being equivalent to a simple sum of their recent affective reactions. Operationally, happiness is defined as a more enduring and chronic state than momentary or daily moods, but is somewhat dynamic and, thus, amenable to meaningful pursuit (Lyubomirsky et al., 2005).

Extensive research on happiness has been carried out during the last three decades (e.g., Luhmann et al., 2012). According to Lyubomirsky and colleagues (2005) some primary characteristics of happy people are: confidence, optimism, self-efficacy, positive construal of others, sociability, immunity and physical health, effective coping with life's stressors, authenticity, and flexibility. Furthermore, happy people tend to be successful and accomplished across multiple life domains (Lyubomirsky, King, \& Diener, 2005). Most people want to be happy (Diener, 2000) and they seek happiness in a variety of ways. Evidence suggests, however, that changing one's life circumstances is not the most fruitful path to greater well-being (Sheldon \& Lyubomirsky, 2006). Instead, simple cognitive and behavioral strategies that people can employ in their daily lives have been found to reliably improve happiness (Sin \& Lyubomirsky, 2009).

Growing attention to the research of happiness and subjective well-being has encouraged the proliferation of several psychometric measures. One of the most widely used measures of happiness is Bradburn's (1969) Affect Balance Scale, which assesses the balance of positive and negative affects experienced during the previous 4 weeks. Thus, the Affect Balance Scale is a measure of the affective component of subjective well-being. Another frequently used measure of subjective well-being is the Satisfaction With Life Scale (SWLS; Diener et al., 1985), which assesses the concept of life satisfaction by measuring individuals' global judgement of their lives and, thus, the cognitive component of subjective well-being. Other measures of subjective well-being include single-item scales, such as Bradburn's (1969) Global Happiness Item or scales that tap into various aspects of psychological functioning in addition to well-being (e.g., Dupuy, 1978). The most recent Subjective Happiness Scale (Lyubomirsky \& Lepper, 1999) assesses the overall "subjective happiness", covering the gap in the literature regarding the need for a measure focused on whether one is a happy or an unhappy person. Lyubomirsky and Lepper (1999) posited "...such a measure would reflect a broader and more molar category of well-being and tap into more global psychological phenomena. ... most individuals are capable of reporting on the extend to which they are a happy person (or unhappy one), and this judgement is likely not equivalent to a simple sum of their recent levels of affect and their satisfaction with life (p. 140)".

Hence, the SHS has been developed in order to offer brief measure of global well- 
being in individuals. The SHS has a number of advantages over other measures aimed at assessing global subjective well-being. Lyubomirsky and Lepper (1999), based on data collected on North American and Russian samples, developed the Subjective Happiness Scale (SHS), which has been found to possess high internal consistency, good to excellent test-retest reliability, a unidimensional structure, and good convergent and discriminant validity. Since then, the SHS has gained increasing popularity and it is currently one of the most commonly used measures of global happiness, in correlational studies involving different self-report scales and health outcomes as criteria (Lyubomirsky et al., 2005).

Many translations and validation studies have been carried out in different countries and languages. Recent works have confirmed the psychometric properties of the English version of the scale (Mattei \& Schaefer, 2004). In addition to the original English and Russian versions (Lyubomirsky \& Lepper, 1999), Subjective Happiness Scale has been translated and validated in German and Tagalog (Swami et al., 2009), Japanese (Shimai et al., 2004), Arabic (Moghnie \& Kazarian, 2012), Portuguese (Spagnoli et al., 2012), French (Salama-Younes, 2011), Malaysian (Swami, 2008), Serbian (Jovanovic, 2013), Spanish (Extremera \& Fernandez-Berrocal, 2014) and Italian (Iani, Lauriola, Layous, \& Sirigatti, 2014). All these adaptations have provided evidence of the construct validity of the scale in various cultural groups, in all cases finding acceptable indicators of temporal stability and adequate levels of internal consistency. Likewise, all the translations have confirmed the unitary structure of the original SHS. The SHS is a 4-item scale rated on a 1 to 7 Likert-type scale that measures global subjective happiness by means of statements, with which participants either self-rate themselves or compare themselves to others. Two items request the individuals to describe themselves using either absolute valuation criteria of their lives or else valuation criteria with regard to others, whereas the other two items present brief descriptions of happy or unhappy individuals and the respondents are asked to indicate the degree to which these descriptions fit them.

Concerning age differences results from several studies suggest no significant statistical differences in SHS scores (Swami et al. 2009). However, some studies found differences in type of college campus (e.g., college youth attending the private universities reported greater happiness scores than those attending the public ones; Moghnie \& Kazarian, 2012), and age groups (e.g., adults reported greater happiness scores than adolescents, and greater happiness than university students; Vera-Villarroel et al., 2012).

Nowadays, it is well known that happy individuals are more successful across multiple life domains than the unhappy ones (Liubomirsky, King, \& Diener, 2005). In general, people tend to perceive themselves in positive emotional states when important areas of their lives are going well. On this perspective, positive affect is a reflex of the positive evaluation of many different areas. These areas and their respective importance are, however, different across cultures, so it is quite difficult to cross-culturally compare the levels of happiness within a specific-domain approach (Diener, 2000). 
The aim of this study is to investigate the psychometric properties of the Greek version of the Subjective Happiness Scale (Lyubomirsky \& Lepper, 1999) in a wide sample of participants. To our knowledge, there is no version validated in Greek, and confirmation of the psychometric properties in this language would provide evidence of the suitability of the scale in different cultural groups.

\section{Method}

\subsection{Participants and Procedure}

The participants in the present study were 6948 Greek adults (2332 men, 33.6\%, 3584 women, $51.6 \%$ and 1032 did not stated their sex, 14.8\%), aging from 18 to 79 years old. The mean age for the total sample was 36.84 years, $S D=13.31$, for men $M_{\text {age }}=37.47$, $S D=13.58$ and for women $M_{\text {age }}=36.00, S D=12.94$. The majority of the respondents were married (3255 married, 46.9\%, 3051 unmarried, 43.9\%, 444 divorced, 6.4\%, 132 widowers, 1.9\%, 65 missing, 0.9\%), employed (5651 employed, 81.3\%, 1236 unemployed, 17.8\%, 60 missing, $0.9 \%$ ) and university graduates (2428 school graduates, $34.9 \%, 832$ university students, $12 \%, 2795$ university graduates, $40.3 \%, 833$ postgraduates, $12 \%, 59$ missing, $0.8 \%$ ).

The present data are a subset of a larger data bank of an ongoing longitudinal study, which started in 2008, examining the effects of the economic crisis on the psychological health of Greeks in relation to several variables including positive and negative emotions. The data used in the present study were collected during 2008 to 2014 . Undergraduate psychology students volunteered to administer the battery of tests. The volunteers were trained on the distribution, administration and collection of the questionnaires. Each student administered the battery of tests to 15 adult individuals among their social milieu. Every year, approximately 100 students participated, resulting in the collection of approximately 1500 participants. Administration was done individually and was completed in approximately 20 minutes. The data were recorded on answer sheets and scanned using the $6^{\text {th }}$ Version of Remark Office OMR.

In order to examine the criterion validity of the test, some participants also filled in other scales, which were used as criteria.

\subsection{Measures}

\subsubsection{Subjective Happiness}

The Greek version of Subjective Happiness Scale (SHS; Lyubomirsky \& Lepper, 1999; Avgoustaki, Dimitriadou, \& Stalikas, 2012b) was used to examine the subjectivity of persons' global happiness using four items rated on a 7-point Likert scale with higher scores reflecting greater happiness.

\subsubsection{Presence of Meaning in Life}

The subscale of Meaning in Life Questionnaire (MLQ; Steger, Frazier, Oishi, \& Kaler, 2006) was used to measure the presence of meaning (how much respondents feel their lives have meaning) using five items rated on a 7-point Likert-type scale ranging from 1 (Absolutely True) to 7 (Absolutely Untrue) (e.g., "My life has a clear sense of purpose"). 
We used the Greek version of the instrument (Pezirkianidis, Galanakis, Karakasidou, \& Stalikas, 2016). In our sample $(N=4145)$, the subscale demonstrated good internal consistency $(\alpha=0.83)$.

\subsubsection{Positive and Negative Emotions}

The mDES (Fredrickson et al., 2003) asks participants to recall the past two weeks and rate their strongest experience of 20 emotions on a 5-point Likert scale (1-Not At All to 5-Extremely). We used the Greek version of the instrument (mDES, Galanakis, Stalikas, Pezirkianidis, \& Karakasidou, 2016). The Greek mDES measures nine positive (joy, hope, love, contentment, pride, interest, gratitude, amusement and sexual desire), eight negative (anger, sadness, disgust, shame, guilt, contempt, embarrassment and fear) and three separate emotions (awe, sympathy and surprise). In our sample $(N=6670)$, the subscales demonstrated adequate internal consistency ( $\alpha=0.75$, Positive Emotions subscale, $\alpha=0.86$, Negative Emotions subscale, $\alpha=0.76)$.

\subsubsection{Life Satisfaction}

The Satisfaction With Life Scale (SWLS; Diener, Emmons, Larsen, \& Griffin, 1985) examines the global assessment of a person's quality of life using five items rated on a 7-point Likert scale ranging from "Strongly Disagree" to "Strongly Agree (e.g., "I am satisfied with my life"). We used the Greek version of the scale (Stalikas \& Lakioti, 2012), which demonstrated good internal consistency in our sample $(\alpha=0.84 ; N=$ 1313).

\subsubsection{Inspiration}

The Inspiration Scale (IS; Thrash \& Elliot, 2003) measures the frequency and the intensity in which individuals feel inspired using eight items rated on a 7-point Likert scale, where higher scores reflect higher levels of inspiration (e.g., "I experience inspiration. How often does this happen?", "I am inspired to do something. How deeply or strongly in general?"). We used the Greek version of the instrument (Avgoustaki, Dimitriadou, \& Stalikas, 2012a; $N=1674)$, which demonstrated high internal consistency $(\alpha=0.94)$.

\subsubsection{Hope}

The Greek version of the Hope Scale (HS; Snyder et al., 1991; Moustaki \& Stalikas, 2012a) was used to measure individuals' sense of successful goal-directed determination and planning of ways to meet goals using eight items rated on a 4-point Likert scale ranging from "Definitely False" to "Definitely True" (e.g., "I energetically pursue my goals", "There are lots of ways around any problem"). In our sample $(N=973)$, the scale demonstrated good internal consistency $(\alpha=0.86)$.

\subsubsection{Psychological Resilience}

The Greek version of the Connor-Davidson Resilience Scale (CD-RISC; Connor \& Davidson, 2003; Dimitriadou \& Stalikas, 2012) was used to measure individuals' stress coping ability and recovery from stress using 25 items rated on a 5-point Likert scale, with higher scores reflecting greater resilience (e.g., "Can handle unpleasant feelings"). 
In our sample $(N=3557)$, the scale demonstrated high internal consistency $(\alpha=0.90)$.

\subsubsection{Psychological Health}

The Greek version of the Depression Anxiety and Stress Scale (DASS; Stalikas \& Flora, 2012; Lovibond \& Lovibond, 1995) consists of 21 items measuring three emotional states (7 items each): depression (e.g., "I couldn't seem to experience any positive feeling at all"), anxiety (e.g., "I found myself in situations that made me so anxious I was most relieved when they ended") and stress (e.g., "I found it difficult to relax"). Each item was rated from 1 (Did Not Apply to Me At All) to 4 (Applied to Me Very Much or Most of the Time). In our sample $(N=6593)$, the three subscales demonstrated high internal consistency ( $\alpha=0.91,0.90$ and 0.90 , respectively).

\subsubsection{Optimism}

The Life Orientation Test (LOT; Scheier \& Carver, 1985) examines individual's tendency to believe that he/she will experience good or bad outcomes in his/her life using eight items rated on a 5-point Likert scale ranging from "Totally Disagree" to "Totally Agree" (e.g., "In Uncertain times, I usually expect the best"). We used the Greek version of the instrument (Moustaki \& Stalikas, 2012b; $N=2299$ ), which demonstrated good internal consistency $(\alpha=0.83)$.

\subsection{Statistical Analysis}

The data collected was analyzed using the Statistical Package for the Social Sciences vol. 21. First of all, we have conducted an item analysis estimating and checking the variances, means and standard deviations of the four items. Then, we checked the item inter-correlations, internal consistency reliability and split-half reliability. The above, provided useful information about the structure of the scale. Moreover, we have created two databases from the original one, in order to conduct an Exploratory Factor Analysis and a Confirmatory Factor Analysis (using IBM SPSS Amos, version 21) so as to finalize the factorial structure of the scale. Finally, we have examined the criterion validity of the scale using as criteria other variables.

\section{Results}

\subsection{Item Analysis}

We estimated variances, means, and standard deviations of the four items of the scale in order to examine item quality and probability of dysfunctional items or polarization. According to the methodological rule we expected variances ranging from 1.5 to 3.0, indicative of a normal distribution regarding the given answers (reports of happiness were rated on a 7-point scale). Moreover, we were expecting means ranging from 3 to 5 also indicative of a normal distribution regarding the answers in the validation sample. Results shown in Table 1 indicate that all items have a normal distribution regarding the sample's answers.

Some concerns can be risen regarding item No.1 (In general, I consider myself:), because it has a somewhat higher mean (5.11). However, it is not unlikely to have such 
higher scores in non-clinical population like ours. The reliability analysis and factor analysis that follow, will provide us further information regarding whether this item poses a threat to the psychometric properties of the scale or not.

\subsection{Item Inter-Correlations}

To further examine item quality, we carried out a correlational analysis between all scale items. According to the methodological rule we were expecting to find positive statistical significant correlations between the items of each subscale ranging from 0.10 to 0.60 . This particular strength and direction of the correlation is indicative of items that measure the same variable and are complementary to one another regarding the factor variable. Negative correlations are indicative of opposite variables measurement, while null correlations are indicative of irrelevancy to the main variable. Extremely high correlations $(r>0.60)$ are indicative of items that probably measure the exact same thing and therefore one of them could be omitted without losing any psychometric properties. Table 2 shows the results of the analysis.

According to the results shown in Table 2, all of the inter-item correlations in the SHS were positive and statistically significant $(p<0.001)$, ranging from $r=0.29$ to 0.68 .

Table 1. Means, standard deviations and variances of the SHS items ( $1=$ Not Happy to $7=$ Very Happy; $N=6948)$.

\begin{tabular}{lccc}
\hline \multicolumn{1}{c}{ Items } & Mean & SD & Variance \\
\hline $\begin{array}{l}\text { 1. In general, I consider myself: } \\
\begin{array}{l}\text { 2. Compared to most of my peers, I consider myself: } \\
\text { 3. Some people are generally very happy. They enjoy life regardless } \\
\text { of what is going on, getting the most out of everything. To what } \\
\text { extent does this characterization describe you? }\end{array}\end{array}$ \\
$\begin{array}{l}\text { 4. Some people are generally not very happy. Although they are } \\
\text { not depressed, they never seem as happy as they might be. To what } \\
\text { extend does this characterization describe you? }\end{array}$ & 4.45 & 1.49 & 2.23 \\
\end{tabular}

Note. Item No. 4 is included to the analysis after being reversed.

Table 2. Inter-item correlations between the Items of the SHS $(N=6948)$.

\begin{tabular}{|c|c|c|c|c|}
\hline & 1. & 2. & 3. & 4. \\
\hline 1. In general, I consider myself: & - & & & \\
\hline 2. Compared to most of my peers, I consider myself: & 0.68 & - & & \\
\hline $\begin{array}{l}\text { 3. Some people are generally very happy. They enjoy life regardless of } \\
\text { what is going on, getting the most out of everything. To what extent } \\
\text { does this characterization describe you? }\end{array}$ & 0.57 & 0.51 & - & \\
\hline $\begin{array}{l}\text { 4. Some people are generally not very happy. Although they are not } \\
\text { depressed, they never seem as happy as they might be. To what } \\
\text { extend does this characterization describe you? }\end{array}$ & 0.34 & 0.29 & 0.37 & - \\
\hline
\end{tabular}

${ }^{\star}$ Every correlation is significant at the 0.001 level, Note: Item No. 4 is included to the analysis after being reversed. 
Higher inter-correlations than expected were found between items 1,2 and 3 ( $r=0.51$ to $r=0.68$, which will be evaluated combined with the reliability and factor analysis results, in order to decide whether one or more of the items is not needed in the questionnaire. The above findings, however, are indicative of adequate construct validity.

\subsection{Reliability}

We estimated the scale reliability using the Cronbach alpha index as well as split half reliability measures. According to the analysis, the SHS can be used as a reliable tool for the assessment of subjective happiness in the Greek population. Specifically, the Cronbach Alpha index for the scale was $a=0.76$. The split half reliability index was Spearman-Brown Coefficient (equal and unequal length) $=0.72$ and Guttman Coefficient $=$ 0.71. Therefore, SHS shows satisfactory reliability indexes.

Further item analysis exploring the possibility to strengthen the scale reliability if any of the items was deleted gave positive results. Hypothetical deletion of item 4 leads to reliability increase to 0.81 . However, SHS consists of only four items. If an item will be deleted, the variance of the subjective happiness structure explained by the scale, could be sharply decreased. For this reason, the above findings will be combined with the factor analysis results, so as to decide whether an item should be excluded.

\subsection{Factor Analysis}

In order to examine the factorial structure of the scale we proceeded, firstly, to Exploratory Factor Analysis and, secondly, to Confirmatory Factor Analysis. We created two databases from the original one $(N=6948)$. The first database consisting of 6245 participants was used in EFA. The second database was used in CFA. It was smaller $(N=$ 743), since fit indices in CFA are affected by huge samples. Based on the factorial structure of the original version of the test we expected factor loadings in a single factor. Table 3 shows the results of the exploratory factor analysis.

According to the factor analysis and the Kaiser criterion (eigenvalues greater than 1)

Table 3. SHS Item loadings.

\begin{tabular}{clc}
\hline Item No. & \multicolumn{1}{c}{ Items } & Factor 1 \\
\hline 1 & $\begin{array}{l}\text { In general, I consider myself: } \\
2\end{array}$ & 0.863 \\
& $\begin{array}{l}\text { Compared to most of my peers, I consider myself: } \\
3\end{array}$ & $\begin{array}{l}\text { Some people are generally very happy. They enjoy life regardless of what is } \\
\text { going on, getting the most out of everything. To what extent does this } \\
\text { characterization describe you? }\end{array}$ \\
& $\begin{array}{l}\text { Some people are generally not very happy. Although they are not de- } \\
\text { pressed, they never seem as happy as they might be. To what extend does } \\
\text { this characterization describe you? }\end{array}$ & 0.824 \\
& $\begin{array}{l}\text { Eigenvalues } \\
\text { Total Variance Explained }\end{array}$ & 2.406 \\
\hline
\end{tabular}

Extraction method: Principal Axis Factoring. 
there seem to be one principal factor in the scale which explains $60.16 \%$ of the variable variance. The same conclusion can also be drawn from the scree plot and the Monte Carlo PCA for Parallel Analysis (only one of the SHS factors' eigenvalues are greater than random eigenvalues). Thus, the exploratory factor analysis confirms the original factorial structure of the scale.

Furthermore, we conducted a Confirmatory Factor Analysis, in order to test whether the original Lyubomirsky and Lepper's (1999) model is consistent with the scale measures in a Greek sample. Results indicated that the original model consisted of four items (and their errors) is confirmed to load in a single factor, the subjective happiness. This loading structure was proved very good fitting. More specifically, model fit indices were great: $C F I=0.99(>0.90), T L I=0.98(>0.90), R M S E A=0.07(<0.08), S R M R=0.02$ $(<0.08)$. Therefore, the original factorial structure of the scale consisted of four items is confirmed. For this reason, we decided not to exclude any of the existent items. Taking everything into account, the Greek version of the SHS shows adequate construct validity.

\subsection{Criterion Validity Analysis}

In order to further examine the validity of the scale we used as criteria other variables. We hypothesized that Subjective Happiness score ( $\mathrm{SH}$ ) would correlate negatively to Negative Emotions (NE), Stress (STR), Depression (DEP) and Anxiety (ANX), and positively to Life Satisfaction (LS), Psychological Resilience (RES), Inspiration (IN), Hope (HO), Optimism (O), Positive Emotions (PE) and Presence of Meaning in life (M). Results are presented in Table 4.

Results indicate that SHS have satisfactory criterion validity. More specifically, SHS showed: a) low to moderate negative correlation to experiencing of negative emotions $(r=-0.35, p<0.001, N=6670)$, stress $(r=-0.30, p<0.001, N=6593)$, depression $(r=$ $-0.43, p<0.001, N=6593)$ and anxiety $(r=-0.28, p<0.001, N=6592), \mathrm{b})$ low positive correlation to optimism $(r=0.11, p<0.001, N=2299)$, and c) moderate positive correlation to life satisfaction $(r=0.61, p<0.001, N=1313)$, psychological resilience $(r=$ $0.51, p<0.001, N=3557)$, inspiration $(r=0.31, p<0.001, N=1674)$, hope $(r=0.45, p$ $<0.001, N=973)$, experiencing of positive emotions $(r=0.48, p<0.001, N=6670)$ and presence of meaning in life $(r=0.40, p<0.001, N=4145)$.

\section{Discussion}

This study provides empirical support for the reliability and validity of the Greek ver-

Table 4. Criterion validity of the SHS (criteria: negative emotions, stress, depression, anxiety, life satisfaction, psychological resilience, inspiration, hope, optimism, positive emotions, presence of meaning).

\begin{tabular}{cccccccccccc}
\hline & NE & STR & DEP & ANX & LS & RES & IN & HO & O & PE & M \\
\hline SH & -0.35 & -0.30 & -0.43 & -0.28 & 0.61 & 0.51 & 0.32 & 0.45 & 0.11 & 0.48 & 0.40 \\
N & 6670 & 6593 & 6593 & 6592 & 1313 & 3557 & 1674 & 973 & 2299 & 6670 & 4145 \\
\hline
\end{tabular}

Every correlation is significant at the 0.001 level. 
sion of the SHS. Adaptation was based on data collected from 6948 individuals residing in urban areas, using common component analysis. Results showed that the scale's items have satisfactory psychometric qualities, thus avoiding polarization issues. Mean scores ranged from 3 to 5 while variance ranged from 1.5 to 3 per item. Mean scores per item in relation to standard deviations and variances are indicative of normal distribution as far as participants' answers are concerned. The item with the highest mean and was No. 1 (In general I consider myself happy). One possible explanation for the high mean of this question may be given based on the fact that it states a somewhat socially desirable condition and by means of social construction, culture, peer pressure and social conformity/compliance people often tend to admit that they are happier than they really are.

To further examine item quality, we estimated item inter correlations expecting positive statistically significant correlations ranging from 0.1 to 0.6 . The analysis showed that correlations between all items ranged from $r=0.29$ to $r=0.68$ as expected. This finding is indicative of construct validity.

As far as reliability is concerned, the scale has satisfactory reliability. Specifically, the Cronbach Alpha index for the scale was $\alpha=0.76$. The split half reliability index for the SHS items was $=0.72$. The analysis also showed that by deleting item No 4 we could increase the reliability of the scale to $\alpha=0.81$. In the end we decided to not proceed with the deletion due to structure and factorial reasons as portrayed in the results section. Furthermore, we believed that by minimizing a 4 item scale to a 3 item scale we would damage the psychometric qualities of SHS. The reason that maybe be lying beside this increase of reliability if we decided to delete Item No. 4 can be seen in the item inter-correlations table as well as in the Factor analysis table. Item No. 4 has the weakestnevertheless positive-correlation to the other 3 items of the scale $(0.3)$ and the lowest loading-eigenvalue to the test's main principal component. This means that it measures subjective happiness but through a way or scope that is different to the way of the other 3 items.

Factorial structure of the SHS was examined through exploratory factor analysis (EFA) and Confirmatory Factor Analysis (CFA). According to the exploratory factor analysis there seems to be one principal factor in the scale which explains $60.16 \%$ of the variable variance (subjective happiness). The same result was found also in the CFA. This finding in aligned with the original validation of the scale as well as with the validation in other countries. The manufacturers of the test believe that subjective happiness is a single dimensioned variable-notion and this belief is also found in the Greek cultural environment, basing the foundation for a globally common concept of subjective happiness.

The study also addressed the issue of criterion validity using as criteria specific variables based on recent bibliography. As expected the SHS was negatively correlated to negative emotions, stress, depression and anxiety. On the other hand, the SHS was positively correlated to life satisfaction, resilience, inspiration, hope, positive emotions and meaning in life. All correlations both positive and negative were statistically signi- 
ficant. The only criterion that leads to a troubling result was optimism. The correlation of subjective happiness to optimism was positive but relatively low. An explanation that can be given to this finding without affecting the validity of the scale is that optimism may be a positive emotion variable but it is mostly consider a trait while subjective happiness is a state. These findings are indicative of the validity of the scale in the Greek population.

Regarding the limitations of our study we should mention that reliability indexes were not calculated using test-retest methodology but only simultaneously using the Cronbach Alpha and Split Half Indexes. Moreover, all criteria validity measures were concurrent while we could also estimate validity measures over a period of time and regarding future results.

The study provides useful insights regarding the utilization of the SHS in future studies in Greek speaking populations and it could enhance positive psychology research in all levels.

We strongly believe that future research regarding the validation of the SHS in the Greek population could focus in more specific and maybe more objective happiness measures (like biodata) while also exploring the cultural differences between different populations regarding happiness experiencing. In all, the SHS-Greek Version can be used as a reliable and valid psychometric tool for the measurement of subjective happiness in the Greek population.

\section{References}

Avgoustaki, A., Dimitriadou, D., \& Stalikas, A. (2012a). The Inspiration Scale (IS). In A. Stalikas, S. Triliva, \& P. Roussi (Eds.), Psychometric Instruments in Greece (2nd ed., p. 739). Athens: Pedio.

Avgoustaki, A., Dimitriadou, D., \& Stalikas, A. (2012b). The Subjective Happiness Scale (SHS). In A. Stalikas, S. Triliva, \& P. Roussi (Eds.), Psychometric Instruments in Greece (2nd ed., p. 777). Athens: Pedio.

Bradburn, N. M. (1969). The Structure of Psychological Well-Being. Oxford: Aldine.

Connor, K. M., \& Davidson, J. R. (2003). Development of a New Resilience Scale: The ConnorDavidson Resilience Scale (CD-RISC). Depression and Anxiety, 18, 76-82. https:/doi.org/10.1002/da.10113

Diener, E. D. (2000). Subjective Well-Being: The Science of Happiness and a Proposal for a National Index. American Psychological Association, 55, 34-43. https:/doi.org/10.1037/0003-066X.55.1.34

Diener, E. D., Emmons, R. A., Larsen, R. J., \& Griffin, S. (1985). The Satisfaction with Life Scale. Journal of Personality Assessment, 49, 71-75. https:/doi.org/10.1207/s15327752jpa4901_13

Diener, E. D., Suh, E. M., Lucas, R. E., \& Smith, H. L. (1999). Subjective Well-Being: Three Decades of Progress. Psychological Bulletin, 125, 276-302.

https:/doi.org/10.1037/0033-2909.125.2.276

Dimitriadou, D., \& Stalikas, A. (2012). Connor-Davidson Resilience Scale (CD-RISC). In A. Stalikas, S. Triliva, \& P. Roussi (Eds.), Psychometric Instruments in Greece (2nd ed., p. 717). Athens: Pedio.

Extremera, N., \& Fernández-Berrocal, P. (2014). The Subjective Happiness Scale: Translation and 
Preliminary Psychometric Evaluation of a Spanish Version. Social Indicators Research, 119, 473-481. https:/doi.org/10.1007/s11205-013-0497-2

Fredrickson, B. L., Tugade, M. M., Waugh, C. E., \& Larkin, G. R. (2003). What Good Are Positive Emotions in Crisis? A Prospective Study of Resilience and Emotions Following the Terrorist Attacks on the United States on September 11th, 2001. Journal of Personality and Social Psychology, 84, 365-376. https:/doi.org/10.1037/0022-3514.84.2.365

Gable, S. L., \& Haidt, J. (2005). What (and Why) Is Positive Psychology? Review of General Psychology, 9, 103-110. https:/doi.org/10.1037/1089-2680.9.2.103

Galanakis, M., Stalikas, A., Pezirkianidis, C., \& Karakasidou, I. (2016). Reliability and Validity of the Modified Differential Emotions Scale (mDES) in a Greek Sample. Psychology, 7, 101-113. https:/doi.org/10.4236/psych.2016.71012

Iani, L., Lauriola, M., Layous, K., \& Sirigatti, S. (2014). Happiness in Italy: Translation, Factorial Structure and Norming of the Subjective Happiness Scale in a Large Community Sample. Social Indicators Research, 118, 953-967. https:/doi.org/10.1007/s11205-013-0468-7

Jovanovic, V., \& Zuljevic, D. (2013). Psychometric Evaluation of the Serbian Version of the Multidimensional Students' Life Satisfaction Scale. Social Indicators Research, 110, 55-69. https:/doi.org/10.1007/s11205-011-9916-4

Lovibond, S. H., \& Lovibond, P. F. (1995). Manual for the Depression Anxiety Stress Scale (2nd ed.). Sydney: Psychology Foundation.

Luhmann, M., Hofmann, W., Eid, M., \& Lucas, R. E. (2012). Subjective Well-Being and Adaptation to Life Events: A Meta-Analysis. Journal of Personality and Social Psychology, 102, 592615. https:/doi.org/10.1037/a0025948

Lyubomirsky, S., \& Lepper, H. S. (1999). A Measure of Subjective Happiness: Preliminary Reliability and Construct Validation. Social Indicators Research, 46, 137-155. https:/doi.org/10.1023/A:1006824100041

Lyubomirsky, S., King, L., \& Diener, E. (2005). The Benefits of Frequent Positive Affect: Does Happiness lead to Success? Psychological Bulletin, 131, 803-855. https:/doi.org/10.1037/0033-2909.131.6.803

Lyubomirsky, S., Sheldon, K. M., \& Schkade, D. (2005). Pursuing Happiness: The Architecture of Sustainable Change. Review of General Psychology, 9, 111-147. https:/doi.org/10.1037/1089-2680.9.2.111

Mattei, D., \& Schaefer, C. E. (2004). An Investigation of Validity of the Subjective Happiness Scale. Psychological Reports, 94, 288-290. https:/doi.org/10.2466/pr0.94.1.288-290

Moghnie, L., \& Kazarian, S. S. (2012). Subjective Happiness of Lebanese College Youth in Lebanon: Factorial Structure and Invariance of the Arabic Subjective Happiness Scale. Social Indicators Research, 109, 203-210. https:/doi.org/10.1007/s11205-011-9895-5

Moustaki, M., \& Stalikas, A. (2012a). The Hope Scale (HS). In A. Stalikas, S. Triliva, \& P. Roussi (Eds.), Psychometric Instruments in Greece (2nd ed., p. 517). Athens: Pedio.

Moustaki, M., \& Stalikas, A. (2012b). The Life Orientation Test (LOT). In A. Stalikas, S. Triliva, \& P. Roussi (Eds.), Psychometric Instruments in Greece (2nd ed., p. 613). Athens: Pedio.

Pezirkianidis, C., Karakasidou, E., Galanakis, M., \& Stalikas, A. (2016). Validation of the Meaning in Life Questionnaire (MLQ) in a Greek Sample. Psychology, 7, 1518-1530. https:/doi.org/10.4236/psych.2016.713148

Salama-Younes, M. (2011). Positive Mental Health, Subjective Vitality and Satisfaction with Life for French Physical Education Students. World Journal of Sport Sciences, 4, 90-97.

Scheier, M. F., \& Carver, C. S. (1985). Optimism, Coping, and Health: Assessment and Implications of Generalized Outcome Expectancies. Health Psychology, 4, 219-247. 
https:/doi.org/10.1037/0278-6133.4.3.219

Seligman, M. E., \& Csikszentmihalyi, M. (2000). Positive Psychology: An Introduction. American Psychological Association, 55, 5-14. https:/doi.org/10.1037/0003-066X.55.1.5

Sheldon, K. M., \& Lyubomirsky, S. (2006). Achieving Sustainable Gains in Happiness: Change Your Actions, Not Your Circumstances. Journal of Happiness Studies, 7, 55-86. https:/doi.org/10.1007/s10902-005-0868-8

Sin, N. L., \& Lyubomirsky, S. (2009). Enhancing Well-Being and Alleviating Depressive Symptoms with Positive Psychology Interventions: A Practice-Friendly Meta-Analysis. Journal of Clinical Psychology, 65, 467-487. https:/doi.org/10.1002/jclp.20593

Snyder, C. R., Harris, C., Anderson, J. R., Holleran, S. A., Irving, L. M., Sigmon, S. T., Harney, P. et al. (1991). The Will and the Ways: Development and Validation of an Individual-Differences Measure of Hope. Journal of Personality and Social Psychology, 60, 570-585. https:/doi.org/10.1037/0022-3514.60.4.570

Spagnoli, P., Caetano, A., \& Silva, A. (2012). Psychometric Properties of a Portuguese veRsion of the Subjective Happiness Scale. Social Indicators Research, 105, 137-143. https:/doi.org/10.1007/s11205-010-9769-2

Stalikas, A., \& Flora, A. (2012). Depression Anxiety Stress Scale (DASS). In A. Stalikas, S. Triliva, \& P. Roussi (Eds.), Psychometric Instruments in Greece (2nd ed., p. 247). Athens: Pedio.

Stalikas, A., \& Lakioti, A. (2012). Satisfaction with Life Scale (SWLS). In A. Stalikas, S. Triliva, \& P. Roussi (Eds.), Psychometric Instruments in Greece (2nd ed., p. 752). Athens: Pedio.

Steger, M. F., \& Frazier, P. (2005). Meaning in Life: One Link in the Chain from Religiousness to Well-Being. Journal of Counseling Psychology, 52, 574-582. https:/doi.org/10.1037/0022-0167.52.4.574

Swami, V., Stieger, S., Voracek, M., Dressler, S. G., Eisma, L., \& Furnham, A. (2009). Psychometric Evaluation of the Tagalog and German Subjective Happiness Scales and a Cross-Cultural Comparison. Social Indicators Research, 93, 393-406. https:/doi.org/10.1007/s11205-008-9331-7

Thrash, T. M., \& Elliot, A. J. (2003). Inspiration as a Psychological Construct. Journal of Personality and Social Psychology, 84, 871-889. https:/doi.org/10.1037/0022-3514.84.4.871

Vera-Villarroel, P., Urzúa, A., Celis-Atenas, P. P. K., \& Silva, J. (2012). Evaluation of Subjective Well-Being: Analysis of the Satisfaction with Life Scale in Chilean Population. Universitas Psychologica, 11, 719-727. 
Submit or recommend next manuscript to SCIRP and we will provide best service for you:

Accepting pre-submission inquiries through Email, Facebook, LinkedIn, Twitter, etc. A wide selection of journals (inclusive of 9 subjects, more than 200 journals)

Providing 24-hour high-quality service

User-friendly online submission system

Fair and swift peer-review system

Efficient typesetting and proofreading procedure

Display of the result of downloads and visits, as well as the number of cited articles

Maximum dissemination of your research work

Submit your manuscript at: http://papersubmission.scirp.org/

Or contact psych@scirp.org 